\title{
Yumatsarika Ipira Mama: objeto educacional para o auxílio da revitalização da Língua Kokama no contexto do ensino remoto
}

\author{
Yumatsarika Ipira Mama: Educational object to support the revitalization \\ of the Kokama language in the remote classes context
}

Vinicius S. Motinha, Mariana da S. Lima, Ana Claudia Maynardes, Lucie A. Nsimba

educação remota, design de informação, kokama, revitalização de línguas indígenas

O artigo apresenta a pesquisa e o desenvolvimento de um material didático para prática pedagógica do ensino da língua Kokama, na modalidade de ensino remoto. Para isso, foi estruturado uma trajetória projetual própria para unificar ferramentas de metodologia de design trabalhadas em moldes não presenciais, com um percurso de co-design juntamente com a professora e coordenadora do projeto de revitalização da referida língua. Como resultado, foi elaborado um jogo de tabuleiro, trabalhando os conteúdos de Marcas de Tempo e Partículas e projetado para ser construído com materiais que os alunos têm acesso em suas casas, devido à situação de confinamento que estão vivendo no momento da pesquisa.

remote education, informational design, kokama, revitalization of indigenous languages

The article presents the research and development of a didactic material for the pedagogical practice of the Kokama language teaching, in the context of remote education. Thus, a particular design trajectory was structured to unify design methodology tools applied in non-presential molds, with a co-design approach with the aforementioned language teacher and revitalization project coordinator. As a result, a board game was developed, working with the contents of Tense Marks and Particles and projected to be made out of materials to which students have access at home, given the confinement situation they are living in at the moment of this research.

\section{Introdução}

Partindo de um contexto de pandemia, o presente trabalho busca investigar o problema do ensino remoto. Numa metapesquisa, a motivação nasceu de um projeto acadêmico para uma disciplina de design da Universidade de Brasília que, no momento da redação desse texto, ocorre completamente de maneira remota.

Para tanto, este projeto contou com a colaboração de Altaci Corrêa Rubim, professora e pesquisadora do Departamento de Linguística, Português e Línguas Clássicas (LIP) do Instituto de Letras (IL) da Universidade de Brasília que integra o Projeto Nova Cartografia Social da Amazônia-PNCSA/UEA, no qual desenvolve uma ação extensionista focada na revitalização da Língua Kokama.

Anais do $10^{\circ} \mathrm{CIDI}$ e $10^{\circ} \mathrm{CONGIC}$

Kelli C.A.S. Smythe, Rafael de Castro Andrade (orgs.)

Sociedade Brasileira de Design da Informação - SBDI

Curitiba | Brasil | 2021
Proceedings of the $10^{\text {th }} \mathrm{CIDI}$ and $10^{\text {th }}$ CONGIC

Kelli C.A.S. Smythe, Rafael de Castro Andrade (orgs.)

Sociedade Brasileira de Design da Informação - SBDI Curitiba | Brazil | 2021 
A presente pesquisa teve como objetivo desenvolver materiais didáticos para prática pedagógica no ensino da língua Kokama que possam ser executados e manipulados à distância, possibilitando assim, o envolvimento de alunos que estão confinados em espaços fechados durante a pandemia do coronavírus.

\section{Fundamentação Teórica}

A fundamentação teórica para o desenvolvimento do projeto foi dividida em três eixos básicos: i) o entendimento acerca da língua Kokama; ii) estudos sobre metodologias de ensino de segunda língua (L2); iii) relação design de informação e educação.

\section{Características do povo e da língua Kokama}

O povo Kokama é caracterizado, prioritariamente, pela autodefinição, com cada comunidade possuindo suas características peculiares e individuais. As comunidades Kokama habitam regiões da Colômbia, Brasil e Peru, em ordem decrescente da concentração de pessoas. Representações culturais importantes para as comunidades são as aves, os animais, os peixes e a floresta, além de suas técnicas desenvolvidas durante o tempo, como o teçume (um artesanato característico feito de talas), as cerâmicas, as armadilhas e instrumentos de caça e pesca (Rubim, 2020).

No que tange o aspecto cultural da língua, o idioma Kokama, atualmente, está restrito, como uso em forma de primeira língua, aos anciãos das aldeias. É exatamente por isso que o projeto de revitalização existe: para garantir que novas gerações Kokama possam entender e se expressar no idioma ancestral. Sua origem ainda é questão de debate acadêmico, com questionamentos sobre o pertencimento do idioma ao subgrupo três do tronco Tupi-Guarani (Rubim, 2020). Em termos estruturais, a língua Kokama é bastante flexível, permitindo diversas ordens sintáticas (como Sujeito-Verbo-Objeto e Objeto-Sujeito-Verbo, por exemplo). Assim, com a aquisição de léxico, estabelecer a comunicação é facilmente inteligível para um falante.

\section{Metodologias para ensino de segunda língua}

Para este projeto, foi utilizado o conhecido método da Abordagem Comunicativa (Richards, 2006) que objetiva o ensino focado no sentido, no significado da língua e suas funções linguísticas, e na interação entre os falantes. Isto é, os propósitos e situações das atividades devem estimular um uso da língua que seja parte de uma funcionalidade real.

Assim, não há uma descontextualização de seus usos nem uma mera redução de seu aprendizado para práticas e métodos de simples repetição e formação sintática mecânicas. Partindo deste princípio, estabelecemos como requisito do projeto o uso coletivo do objeto final, para possibilitar a inserção dos indivíduos em contexto de uso interacional do idioma. 


\section{Relação design e educação}

Segundo Coutinho e Lopes (2011, p.11) ao aproximarmos o campo da educação ao campo do design, estamos a caminho da construção de um pensamento social, voltado para a articulação de princípios de design que contribuam com as práticas educacionais. Assim, duas vertentes do design podem ser consideradas: a primeira, refere-se ao uso da forma de pensar design junto à formação dos indivíduos. A segunda diz respeito à forma de fazer design, enquanto atividade projetual, na solução de problemas referentes aos artefatos mediadores de aprendizagem.

As autoras também defendem que o designer pode auxiliar diretamente o professor na produção de conteúdos que visam melhorar o ensino em sala de aula e a compreensão dos alunos sobre a disciplina. Nesse sentido, professores e alunos são geradores de informação gráfica. Para tanto, conceitos de design da informação e design instrucional foram utilizados para o desenvolvimento da pesquisa, principalmente no que tange ao entendimento do léxico da língua Kokama e sua representação gráfica.

\section{Metodologia}

Para o desenvolvimento do projeto duas etapas foram bem definidas. A primeira, de caráter exploratório e bibliográfico, que buscou por referenciais teóricos acerca da língua Kokama; de métodos de ensino de línguas, seja como L1 ou como L2; e, por último, de métodos acessíveis adotados através da prática do design para educação de línguas.

A segunda etapa diz respeito às metodologias de design para auxiliar a prática projetual e a busca de resultados práticos. Dessa maneira, esta etapa teve cunho exploratório e se baseou na metodologia Extensible Design Methods (XMD) de Neves et al. (2008), que prevê o uso de ferramentas virtuais para a elaboração das etapas de projeto.

Assim, o processo foi dividido em quatro etapas: exploração do problema; geração de alternativas; seleção e avaliação de alternativas; por fim, descrição da solução final. Cabe aqui ressaltar que a professora Altaci Rubim participou efetivamente de todas as etapas.

\section{Resultado e Discussão}

Em sala de aula, os professores do idioma notaram a necessidade de dividir os alunos em grupos de faixa etária, que receberam os nomes de peixes importantes em seus cotidianos (Sardinhas, Pacus, Botos, Piraíbas e Pirarucus, em ordem crescente).

A metodologia de ensino utilizada é chamada de "Estrela" (Tsetsu) porque se baseia em cinco pontos: Visualidade, Contextualização, Oralidade, Escrita e Audição. Esses aspectos são somados à metodologia comunicativa e sócio-interacional. $\mathrm{O}$ idioma Kokama se utiliza de ferramentas de linguagem que não são comuns ao Português do Brasil, como o uso de partículas e marcas de tempo um pouco distintas. 
Dentro dessa perspectiva, o objeto a ser projetado precisaria seguir alguns parâmetros, sendo que os principais foram:

- Trabalhar com informações visuais com propósito de apoio lúdico à maneira tradicional de ensino da língua (visualidade é considerada importante para o engajamento indígena);

- Tendo em vista a forma de compartilhamento assíncrona, tanto a confecção do objeto quanto seu uso precisam ser claros e simples de explicar; e

- Associado à simplicidade, devido às condições contextuais dos usuários, o objeto precisa ter um baixo custo econômico, baixo custo de tempo de execução, baixo custo cognitivo e baixo custo para o planeta;

- Os usuários seriam os professores da Língua Kokama (passivos) e os alunos do curso (ativos); grupos de faixa etária Pacus (9-12 anos) e Botos (13-17 anos).

O projeto teve foco intenso na simplificação de ideias que viabilizassem tanto a construção, quanto o uso do jogo de modo remoto. Assim, com base nos parâmetros e requisitos estabelecidos acima, o objeto final tornou-se a concretização de um jogo de tabuleiro que pudesse ser desenvolvido com o uso de um pouco menos de duas folhas A4 de papel comum dobradas, podendo ser decorado com quaisquer materiais artísticos disponíveis.

Em termos de mecânica e ambientação, recebeu o nome de Yumatsarika Ipira Mama (Jogo da mãe dos peixes, em Kokama) e segue uma narrativa originalmente Kokama, com liberdades poéticas na situação geral do jogo. O aluno, que se vê preso de um dos lados de um rio, pede a ajuda da mãe dos peixes: uma cobra enorme que liga cada uma das margens. Para atravessar o rio, o aluno precisa responder corretamente às perguntas dadas a ele, atribuídas em cada uma das casas. Num jogo com fim competitivo entre alunos, aquele que chegar a outra margem primeiro vence. As perguntas são o principal instrumento para aprendizado, que pode ser usado de maneira estratégica pelos professores a fim de adaptar as questões com aquilo que está sendo tratado em aula.

Figura 1: Alternativa final do jogo

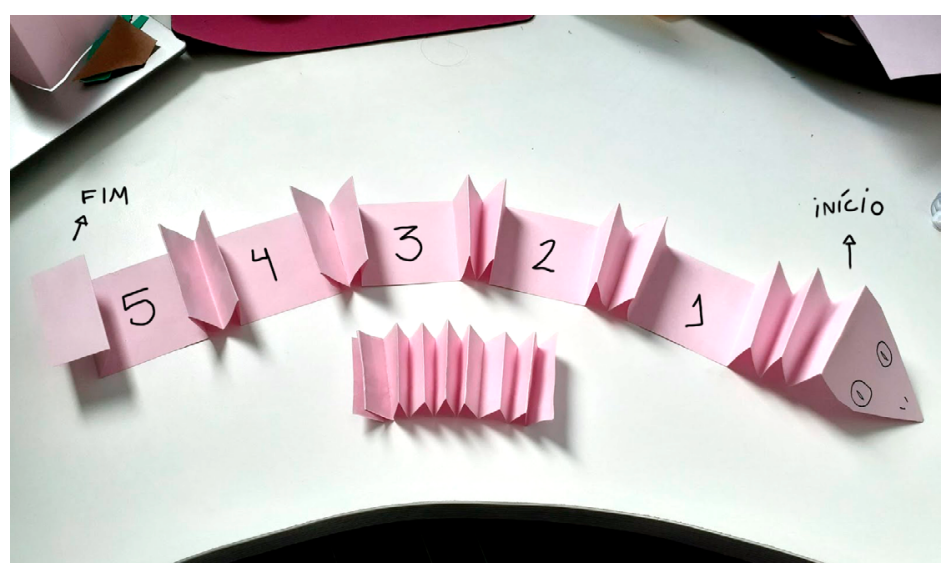

Fonte: Elaborado pelos autores 
Com objetivo similar de atravessar um tabuleiro com casas, o jogo pode ser definido como um tabuleiro de cinco casas (que são módulos soltos encaixados um ao outro), cada uma delas designando uma pergunta desafio. Aquele que, na sua vez, acertar, avança uma casa; se errar, volta ao início. Para dar mais volatilidade ao jogo, foi criado o artifício do dado de ações. Nele, existem 4 possíveis resultados: responder a uma pergunta, pular a vez, responder a duas perguntas (e andar duas casas em uma só jogada) e voltar do início sem chance de responder. Assim, o fator sorte é adicionado, aumentando o desafio e a ludicidade do objeto.

Figura 2: Módulos para montagem do tabuleiro.
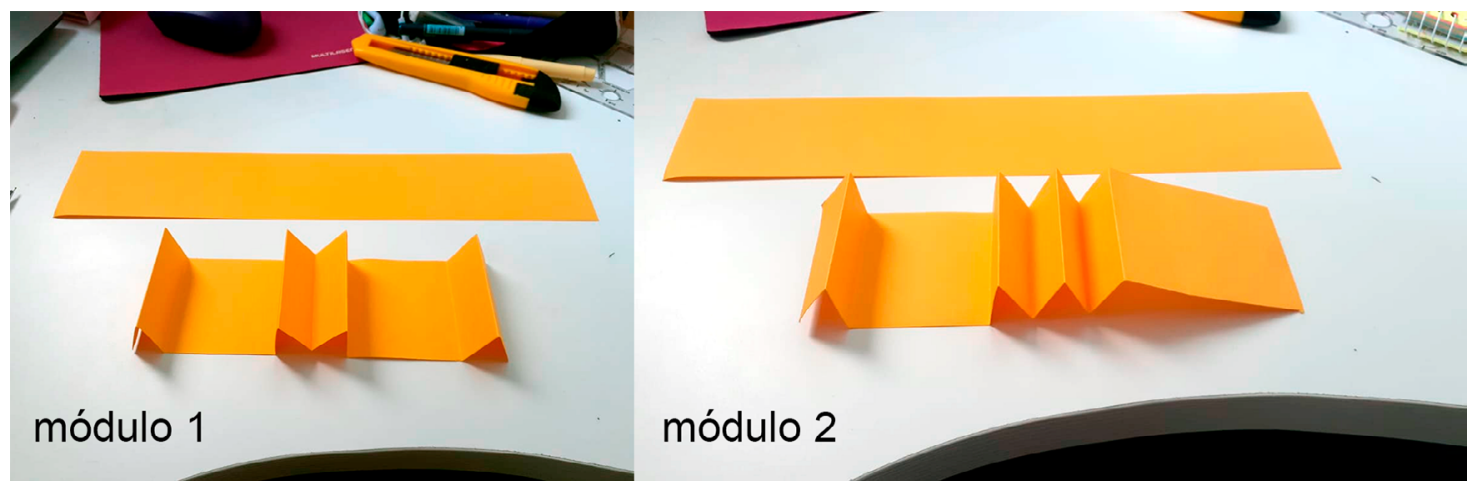

Fonte: Elaborado pelos autores

Podemos destacar que a utilização do formato da "cobra" proporcionou a inserção de um forte elemento cultural do povo Kokama como informação e estímulo visual; fez que cada módulo de papel assumisse, ao mesmo tempo, as funções das casas do tabuleiro e peças do jogo; assim como contribuiu para o ensino focado no sentido, no significado da língua e suas funções linguísticas.

Figura 3: Sugestão de decoração.
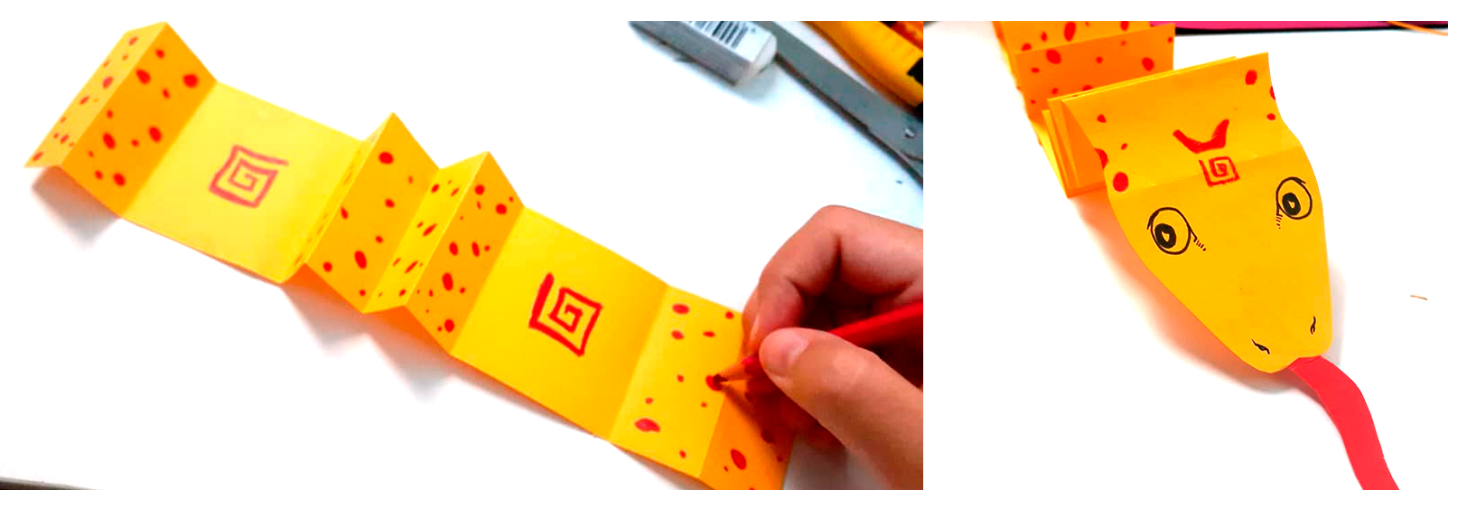

Fonte: Elaborado pelos autores

Para finalizar todo o processo, foi desenvolvido um manual de construção e regras do jogo em formato digital que permite fácil leitura em smartphones. da língua Kokama e sua representação gráfica. 


\section{Considerações Finais}

A partir dos requisitos acumulados no decorrer do projeto foi possível concretizar uma estratégia de ensino da língua Kokama para o ambiente remoto. O processo se baseou em metodologias ativas (REF) de aprendizado de línguas, usando o artifício do objeto tridimensional, juntamente com a viabilidade dos materiais e disponibilidade no ambiente que os alunos residem.

Durante o processo, foram analisadas estratégias de ensino de línguas L2 já disponíveis para outros idiomas e como os professores dessas disciplinas se utilizam dos jogos para manter a atenção e trazer melhorias no ensino.

Por fim, utilizar o design para potencializar o processo de construção de conhecimento por meio da interação e da ludicidade promove e sustenta as relações educativas, estimula maior diálogo entre professor e aluno e, principalmente, cria processos de ensino-aprendizagem mais estimulantes.

\section{Referências}

Coutinho, S. G., \& Lopes, M. T. (2011). Design para educação: uma possível contribuição para o ensino fundamental brasileiro. O Papel social do design gráfico: história, conceitos \& atuação profissional. São Paulo: Editora SENAC, 137-162.

Neves, A., Campos, F. F. C., Barros, S. G., Campello, S. B., Aragão, I., \& Castillo, L. (2008). XDM: Métodos Extensíveis de Design. In Congresso Brasileiro de Pesquisa e Desenvolvimento em Design (Vol. 8, pp. 249-259).

Richards, J. C. (2006). O ensino comunicativo de línguas estrangeiras. Special Book Services, SBS.

Rubim, A. (2020). Vitalization of the Kokama language beyond the borders of Brazil and Peru. Cadernos De Linguística, 1(3), 01-18. https://doi.org/10.25189/2675-4916.2020.v1.n3.id268 